\title{
Experimental study of thermal processing of solid waste
}

\author{
Olga Kolibaba ${ }^{1, *}$, Ramil Gabitov ${ }^{1}$ \\ ${ }^{1}$ Ivanovo State Power Engineering University, 153003 Ivanovo, Russia
}

\begin{abstract}
In order to develop ways to improve the efficiency of an energy use in thermal reactors, a thermal analysis of the municipal solid waste (MSW) mixture average morphological structure and its components was spent. Experimental studies performed on synchronous termoanalizatore NETZSCH STA 449 F3 Jupiter, combined with a quadrupole mass spectrometer QMC 403. According to the results of the experiments, the temperature ranges of the pyrolysis process and the speed of the mass loss of the sample during solid waste drying and oxidative pyrolysis, thermal effects that accompany these processes, as well as the composition and volume of gases produced in the oxidative pyrolysis of solid waste and its components in the environment oxygen content of $1 \%$ and $10 \%$ were determined.
\end{abstract}

\section{Introduction}

One of the main directions of Russian energy policy is the use of renewable energy sources. These sources include solid organic waste, including household (MSW). The energy use of this raw material allows us to solve a number of problems, such as receiving a gaseous fuel, reducing harmful effects on the environment, involvement in economic turnover of land released from landfills and other.

Currently, there is the possibility of cost-effective, environmentally safe and technically available to recycle MSW without pre-screening using thermal methods, including pyrolysis.

The MSW recycling technologies use different schemes of the pyrolysis installations [1], for example, shaft furnaces in which the pyrolysis is accompanied by a small air leak (oxidative pyrolysis). Oxidative pyrolysis method with subsequent burning of the pyrolysis gases is universal and does not depend on the fractional composition of the waste and a phase condition, their moisture and ash content. At the same time, the products of combustion of pyrolysis gases is less contaminated with fly ash and soot as compared to the direct burning of solid waste, which greatly simplifies the scheme of gas purification.

To improve the efficiency of recycling MSW by oxidative pyrolysis the important task is the experimental study of this process in order to evaluate the influence of several parameters (moisture content of the feedstock, the composition of solid waste, oxygen

\footnotetext{
* Corresponding author: koli-baba@mail.ru
} 
increase in the atmosphere, and others.) on the gas discharge and composition of the pyrolysis gases [2].

\section{Statement of the Problem}

Carrying out the thermal analysis of the mixture of MSW average morphological structure and its components for the development of ways to improve the efficiency of its energy use in heat technologies.

As methods of thermal analysis to study MSW oxidative pyrolysis are used:

- thermal gravimetric analysis (TG - analysis) [3], during which the change in mass of the test sample at a change in temperature was recorded continuously;

- differential scanning calorimetry (DSC), during which the thermal effects, which were accompanied by chemical and phase transformations in the sample heating were recorded continuously;

- mass spectrometry gas mixtures (MS - analysis).

Studies oxidative pyrolysis were conducted for samples of the MSW mixture the average morphological composition (paper - $43 \%$ food waste $-42 \%$, textile waste $-7.5 \%$, and polyethylene - 7.5\%) [4], and the individual components of the mixture in an atmosphere having an oxygen content of $1 \%$ and $10 \%$. Experimental studies were carried out using synchronous thermal analysis complex NETZSCH. Measuring complex consists of a block of thermal analysis STA 449 F3 Jupiter, Quadrupole Mass Spectrometer QMS $403 \mathrm{C}$ Aeolos unit and pulse thermal analysis PulseTA.

Synchronous TG - termoanalizator DSC analysis allows to simultaneously measure heat flow and change in weight of the sample depending on the temperature or time. Simultaneous analysis allows not only process a large number of measurements, but also simplifies the interpretation of the results, by enabling to separate endothermic and exothermic processes, which is not accompanied by a change in mass, from processes where mass change takes place.

As a result of the thermal analysis, so-called thermogravimetric (TG) curves - the dependence of the sample mass on the temperature or time are obtained. Based on the value of the derivative of the TG curve (differential thermal gravimetric analysis - DTG), you can find the temperature or the time interval at which the maximum reduction in sample mass takes place.

\section{Experiment and processing}

By the differential scanning calorimetry (DSC) the amount of heat which is released or absorbed in the chemical reactions was determined. The composition of gas released in pyrolysis is determined by mass - spectrometer QMC 403.

Experimental studies of oxidative pyrolysis was carried out in the following sequence. MSW sample was charged in a platinum crucible, which was mounted on a microbalance in the first cell of the differential scanning DSC sensor. The second comparison sample cell was placed - the crucible without sample (reference). Etalon (crucible without sample) was placed in the second slot. The presence of a double measuring cell allows you to compensate for outside influences (processes associated with heat or heat absorption) on the measurement result. Heat was applied by electric heater in chamber in which the samples were installed. Sample weight ranged $3 \div 15 \mathrm{mg}$. A test sample temperature was measured by differential thermocouples placed on the bottom surface of the crucible, which were connected to the secondary device. Heating was performed in an inert gas (argon) atmosphere, an oxygen-enriched $\left(10 \%\right.$ or 1 vol.) of $20^{\circ} \mathrm{C}$ to $900^{\circ} \mathrm{C}$ at $5^{\circ} \mathrm{C} / \mathrm{min}$. 
During the experiment, the STA 449 F3 Jupiter continuously recorded decline MSW mass of the sample in the process of heating (TG curve), the temperature of the sample and the DSC signal. Maximum sensitivity of the device by weight was $0.1 \mathrm{~g}$ and at a temperature of $-0.001^{\circ} \mathrm{C}$.

The qualitative composition of the pyrolysis products was determined with the help of the Quadrupole Mass Spectrometer QMS 403C Aëolos by finding the partial pressure of the individual components of the gas mixture. Separation of the mixture components was produced by its ionization current. A beam of gas ions by using an electric field accelerates to high speed and passes through a quadrupole mass analyzer, which consists of four metal rods, to which a voltage is applied so that at any one time through the analyzer flying ions with only one ratio of mass to charge ratio $-\mathrm{M} / \mathrm{z}$.

The process of data collection and processing was automated by means of the device software NETZSCH Proteus Thermal Analysis.

The quantitative composition of the pyrolysis gas is determined by internal standard method [5], according to which test compounds are compared with the signal intensity of the standard substance signal (calibration gas), and to calculate the mass fractions of pyrolysis gas components, the methodology proposed by Kozlov A.N. and Keiko A.V. was used [6].

According to this procedure, the amount of substance of $i$ - th the pyrolysis gas component is determined by the formula:

$$
n_{i}=\frac{S_{i}}{k_{i}^{0}}
$$

where: $S_{i}$ - the peak area under the ion current curve of $i$ - th the pyrolysis gas component $\left(\mathrm{CO}, \mathrm{CH}_{4}, \mathrm{H}_{2}, \mathrm{CO}_{2}, \mathrm{H}_{2} \mathrm{O}\right)$ (Fig. 3), A - s; $k_{i}^{0}$ - calibration factor $\mathrm{i}$ - th the pyrolysis gas component.

The area under the peak of the ion current curve $i$ - th component of pyrolysis gas by the formula:

$$
S_{i}=\int_{\tau 1}^{\tau 2} I_{i} d \tau
$$

where: $I$ - ion current, A; $T$ - time, s.

The calibration factor $\mathrm{i}$ - th the pyrolysis gas component is calculated by the formula [9]:

$$
k_{i}^{0}=\frac{S_{i}^{0} \cdot 10^{8} \cdot R_{\mu} \cdot T^{0}}{P^{0} \cdot V_{i}^{0} \cdot x_{i}^{0}}
$$

where $i$ - index of the component (CO, $\mathrm{CH} 4, \mathrm{H} 2, \mathrm{CO} 2, \mathrm{H} 2 \mathrm{O}) ; S_{i}^{0}$ - peak area under the curve of the ion current calibration gas, $\mathrm{A} \bullet \mathrm{s} ; R_{\mu}-$ universal gas constant, $\mathrm{J} / \mathrm{mol} \bullet \mathrm{K} ; V_{i}^{0}-$ volume of calibration gas, $\mathrm{m} 3 ; P_{i}^{0} \quad$ - gas pressure at the inlet of the device, $\mathrm{Pa} ; T^{0}$ - gas temperature at the inlet of the device, ${ }^{\circ} \mathrm{C} ; x_{i}^{0}$ - concentration of a component in calibration gas, $\%$.

The calculation of the calorific value of the pyrolysis gas is formed on the principle of additive:

$$
Q_{n}^{r}=Q_{C H 4} \cdot g_{C H 4}+Q_{C O} \cdot g_{C O}+Q_{H 2} \cdot g_{H 2}
$$


where: $Q_{C H 4}, Q_{C O}, Q_{H 2}$ - calorific value of methane, carbon monoxide and hydrogen, respectively, $\mathrm{J} / \mathrm{kg} ; g_{\mathrm{CH} 4}, g_{\mathrm{CO}}, g_{\mathrm{H}_{2}}$ - mass fractions of methane, carbon monoxide and hydrogen, respectively.

\section{Results and Discussion}

The thermal analysis results of the sample SHW mixture consisting of paper, textile, food waste, and a polymeric film is shown in Fig.1 as DSC, TG and DTG curves.

The results of TG analysis (TG curve) showed that the curve of a sample mass change during heating may be divided into several distinguishing intervals. The first temperature interval from $20^{\circ} \mathrm{C} \div 220^{\circ} \mathrm{C}$ is characterized by a slight change in mass of the sample $(0.5$ to $8 \%$ ) due to evaporation of physical and bound moisture from the surface of the porous structure of the material. With further increase in temperature to $320-330^{\circ} \mathrm{C}$, a sufficiently rapid decrease in mass takes place due to thermal decomposition of the substance and volatile compounds formation. When the temperature reached $330^{\circ} \mathrm{C}$ the mass change curve (Line 1 in Fig. 1) has a distinct bend, which demonstrates decreasing release rate of volatile compounds. At a temperature of $490^{\circ} \mathrm{C}$, a sharp drop in the mass loss rate of the substance, slowing of the thermal decomposition of solid waste, takes place. At a temperature of $540^{\circ} \mathrm{C}$ volatile content ends.

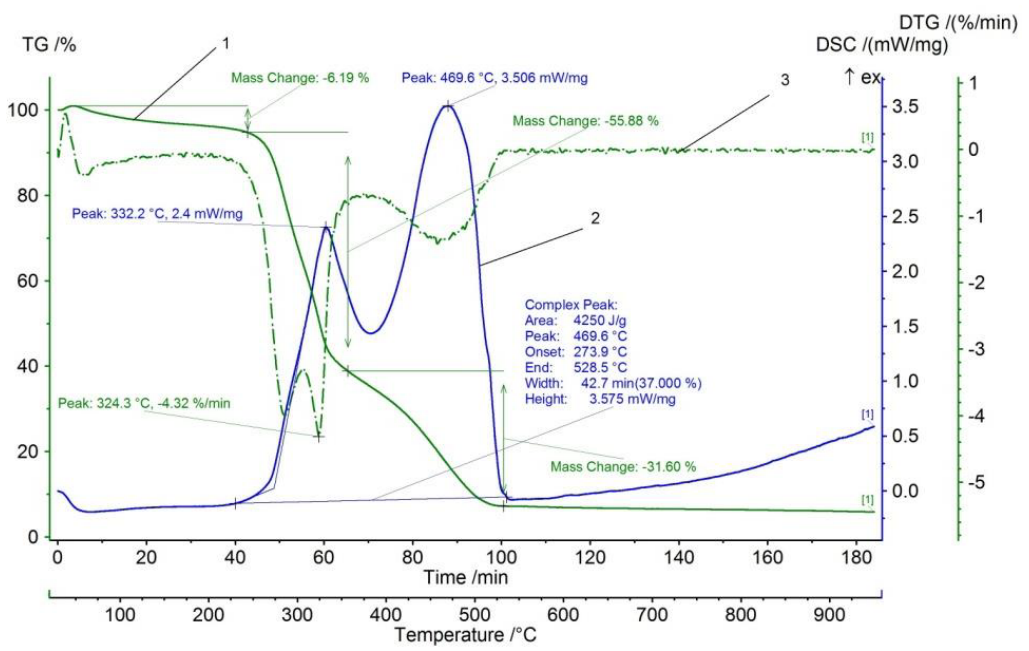

Fig. 1. Curves 1 TG 2 - DSC and 3 - DTG for MSW samples at an oxygen content in the atmosphere of $1 \%$.

Results of differential scanning calorimetry (line 2 in Fig. 1) show that at temperatures up to $220^{\circ} \mathrm{C}$ endothermic processes associated with evaporation of moisture occur in the samples. With further increase of the sample temperature exothermic processes occur.

The DSC curve (line 2 in Fig.1) has two evident exothermic peak at temperatures of $330^{\circ} \mathrm{C}$ and $470^{\circ} \mathrm{C}$. The function then begins to decrease sharply. This indicates that the intensity of exothermic processes is reduced.

The results of differential thermogravimetric analysis (lane 3 in Fig. 1) showed that the maximum decrease in sample mass takes place at temperatures of $330^{\circ} \mathrm{C}$ and $470{ }^{\circ} \mathrm{C}$, which corresponds to the maximum output of the gas phase MSW pyrolysis.

A similar experiment was performed in an environment with oxygen content of $10 \%$, that intensifies pyrolysis process. The thermal analysis results of the pyrolysis MSW 
mixture and its individual components in an environment with an oxygen content of $1 \%$ and $10 \%$ are given in Table 1.

Table 1. Results of thermal analysis of solid waste and its component.

\begin{tabular}{|l|l|l|l|l|l|l|l|l|l|l|}
\hline $\mathrm{N}$ & \multicolumn{2}{|l|}{$\begin{array}{l}\text { Temperatures of the } \\
\text { beginning and end } \\
\text { of the pyrolysis } \\
\text { process, }{ }^{\circ} \mathrm{C}\end{array}$} & $\begin{array}{l}\text { Energy } \\
\text { release peak } \\
\text { temperature, } \\
{ }^{\circ} \mathrm{C}\end{array}$ & \multicolumn{2}{l|}{$\begin{array}{l}\text { Residual } \\
\text { weight, \% }\end{array}$} & \multicolumn{2}{l}{$\begin{array}{l}\text { Maximum } \\
\text { rate of } \\
\text { weight loss, } \\
\% / \text { min }\end{array}$} & $\begin{array}{l}\text { Thermal } \\
\text { effect of } \\
\text { pyrolysis, } \\
\mathrm{J} / \mathrm{g}\end{array}$ \\
\hline $\mathrm{O}_{2}$ & $1 \%$ & $10 \%$ & $1 \%$ & $10 \%$ & $1 \%$ & $10 \%$ & $1 \%$ & $10 \%$ & $1 \%$ & $10 \%$ \\
\hline $\mathrm{MSW}$ & $225 \div 540$ & $215 \div 550$ & 469 & 454 & 6.48 & 6.49 & 4.27 & 5.89 & 4250 & 6685 \\
\hline Paper & $245 \div 492$ & $245 \div 488$ & 477 & 444 & 10.8 & 9.69 & 6.06 & 6.61 & 4951 & 6624 \\
\hline Potatoes & $225 \div 540$ & $215 \div 550$ & 511 & 511 & 3.8 & 4.13 & 5.29 & 6.75 & 3672 & 6696 \\
\hline Polyethylene & $340 \div 540$ & $280 \div 550$ & 395 & 375 & 10.01 & 9.96 & 6.67 & 5.23 & 3954 & 8685 \\
\hline Textile & $240 \div 500$ & $240 \div 490$ & 345 & 336 & 14.34 & 13.43 & 10.4 & 8.68 & 4376 & 5925 \\
\hline
\end{tabular}

The qualitative composition of the pyrolysis gas is obtained by treatment of the mass spectrometer signals (ion current as a function of temperature) distributed in the mass numbers (Fig.2). Figure 2 shows the results of measurements in the MSW pyrolysis in an atmosphere with oxygen content of $1 \%$.

Similar experiments were performed for MSW pyrolysis in an atmosphere with oxygen content of $10 \%$

The experimental results are presented graphically in Fig. 2.
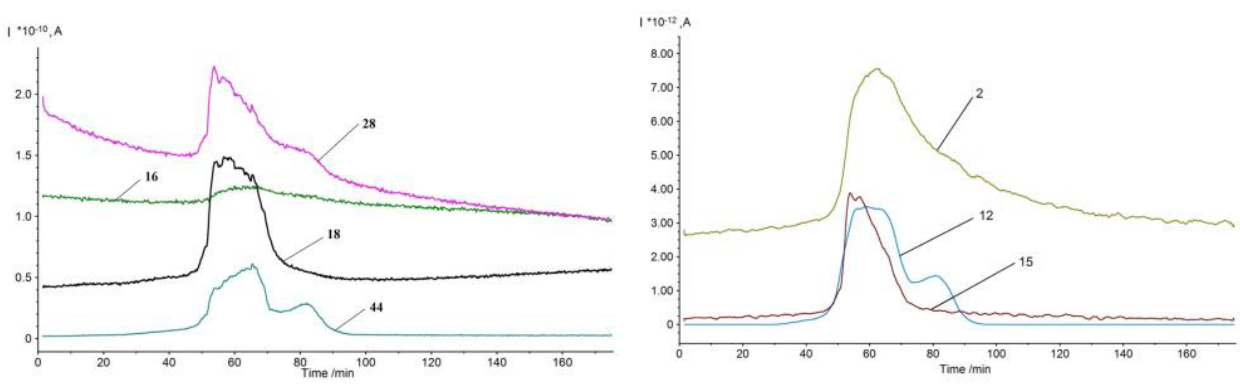

Fig. 2. Mass spectrum of gas formed during MSW pyrolysis in an atmosphere with oxygen content of $1 \%$ : a) gases with a high value mass - spectrometer signal, b) gases with a low value of the mass spectrometer signal (The numbers on the curves indicate the mass number).

To identify the components of the pyrolysis gas, base mass spectrometers NIST data [7], containing information on the mass spectrum of substances were used.

Analysis of Fig. 2 shows that the main components of the pyrolysis gas are: $\mathrm{H}_{2}(2), \mathrm{CH} 4$ (16), $\mathrm{H}_{2} \mathrm{O}$ (18), $\mathrm{CO}$ (28), $\mathrm{CO}_{2}$ (44). The contribution of other components with mass numbers $12,13,14,15,17$ and 46 in a mass component of the main components is determined by comparison with the results presented in the databases NIST.

Table 2 shows the mass spectrum data of the main components of the gas mixture in the form: Experiment / mass basic value - NIST spectra.

Table 2. Comparison of experimental data with NIST database.

\begin{tabular}{|l|l|l|l|l|l|l|l|l|l|l|}
\hline m.ch. & 2 & 12 & 13 & 14 & 15 & 16 & 17 & 18 & 28 & 44 \\
\hline $\mathrm{H}_{2}$ & 100 & - & - & - & - & - & - & - & - & - \\
\hline $\mathrm{CH}_{4}$ & - & $2.8 / 3$ & $6.8 / 8$ & $17 / 20$ & $80 / 87$ & 100 & - & - & - & - \\
\hline $\mathrm{CO}$ & - & $4.5 / 5$ & - & - & - & $0.8 / 1.1$ & - & - & 100 & - \\
\hline $\mathrm{H}_{2} \mathrm{O}$ & - & $7.9 / 9$ & - & - & - & $0.7 / 1$ & $20 / 23$ & 100 & - & - \\
\hline $\mathrm{CO}_{2}$ & - & - & - & - & - & $8.8 / 9$ & - & - & $10 / 13$ & 100 \\
\hline
\end{tabular}


Table 3 shows the qualitative and quantitative composition of gas released in the process of oxidative pyrolysis with oxygen in the atmosphere of $1 \%$ and $10 \%$.

Table 3. Mass fractions of the main components of the pyrolysis gas, $\%$.

\begin{tabular}{|c|c|c|c|c|c|c|c|c|c|c|}
\hline $\mathrm{N}$ & \multicolumn{2}{|c|}{$\mathrm{CH}_{4}$} & \multicolumn{2}{c|}{$\mathrm{CO}$} & \multicolumn{2}{c|}{$\mathrm{H}_{2} \mathrm{O}$} & \multicolumn{2}{c|}{$\mathrm{CO}_{2}$} & \multicolumn{2}{c|}{$\mathrm{H}_{2}$} \\
\hline $\mathrm{O}_{2}$ & $1 \%$ & $10 \%$ & $1 \%$ & $10 \%$ & $1 \%$ & $10 \%$ & $1 \%$ & $10 \%$ & $1 \%$ & $10 \%$ \\
\hline $\mathrm{MSW}$ & 22.5 & 11.93 & 41.25 & 32.91 & 18.9 & 26.66 & 17.21 & 28.47 & 0.14 & 0.03 \\
\hline Paper & 20.7 & 11 & 52.51 & 44.59 & 13.84 & 19.64 & 12.9 & 24.75 & 0.05 & 0.02 \\
\hline Potatoes & 22.94 & 14 & 32.52 & 22.55 & 22.34 & 32.34 & 22.11 & 31.08 & 0.09 & 0.03 \\
\hline Polyethylene & 16.24 & 7.2 & 41.89 & 35.82 & 20.58 & 26.98 & 20.48 & 29.94 & 0.81 & 0.06 \\
\hline Textile & 21.82 & 9.32 & 45.05 & 29.93 & 20.28 & 29.75 & 12.78 & 30.99 & 0.07 & 0.01 \\
\hline
\end{tabular}

The calculation results of the combustible gas calorific value produced in the oxidative pyrolysis in an atmosphere having an oxygen content of $1 \%$ and $10 \%$ are shown in table. 4 .

Table 4. The calorific value of the pyrolysis gas.

\begin{tabular}{|c|c|c|}
\hline $\mathrm{O}_{2}$ & $1 \%, \mathrm{Q}, \mathrm{MJ} / \mathrm{kg}$ & $10 \%, \mathrm{Q}, \mathrm{MJ} / \mathrm{kg}$ \\
\hline $\mathrm{MSW}$ & 16.73 & 10.00 \\
\hline Paper & 16.44 & 10.64 \\
\hline Potatoes & 16.12 & 10.10 \\
\hline Textile & 13.40 & 7.70 \\
\hline Polyethylene & 15.71 & 8.30 \\
\hline
\end{tabular}

The oxidative MSW pyrolysis in an atmosphere with oxygen content of $1 \%$ is characterized by a high content of carbon monoxide (up to $42 \%$ by mass). In this process gas calorific value was $16.8 \mathrm{MJ} / \mathrm{kg}$ and heat (pyrolysis effect) of $4.25 \mathrm{MJ} / \mathrm{kg}$.

In the oxidative MSW pyrolysis of in an atmosphere with oxygen content of $10 \%$ calorific value of the pyrolysis gas was $10 \mathrm{MJ} / \mathrm{kg}$ and heat of $6.7 \mathrm{MJ} / \mathrm{kg}$.

\section{Conclusions}

1. Thermal analysis of the process of oxidative pyrolysis of a SDW mixture of average morphological structure and its components with an oxygen content in the atmosphere of $1 \%$ and $10 \%$ is performed. As the result, the data on the output of the volatile compounds, the maximum rate of weight loss and temperature of heat peaks were obtained.

2. Oxidative pyrolysis in the presence of oxygen in the working zone of the reactor $1 \%$ is accompanied by a thermal effect less than pyrolysis with oxygen content of $10 \%$, but it is formed over caloric pyrolysis gas.

3. The composition and volumes of gases produced by oxidative pyrolysis of MSW mixture average morphological structure and its individual components are experimentally determined.

4. The results of experimental studies of oxidative pyrolysis can be used to calculate the design and operational parameters of the thermal reactor for processing solid waste.

\section{References}

1. P. Basu, Biomass gasification and pyrolysis. Practical design and Theory (Academic Press., N.Y., 2010)

2. G.V. Kuznetsov, M.A. Polsongkram, J. Scientific - Technical Gazette Volga, 1, 125 (2011)

3. W. Wendland, Thermal methods of analysis (Mir, Moscow, 1978) 
4. Thermal utilization of solid household waste, Krasnoyarsk (2006)

5. A.T. Lebedev, Mass spectrometry of organic chemistry (BINOM, Moscow, 2003) [In Russian]

6. A.N. Kozlov, D.A. Svishchev, I.G. Donskoi, A.V. Keiko, J. Journal Thermal Analysis and Calorimetry 3, 1311 (2012)

7. An open database of mass spectra of NIST : http: //webbook.nist.gov/chemistry 